\title{
Class II (laminar flow) biological safety cabinet
}

\author{
S. W. B. NEWSOM
}

From the Sims Woodhead Mèmorial Laboratory, Papworth Hospital, Cambridge CB3 8RE, UK

SUMMARY A microbiological survey of the effectiveness of class II (laminar flow) 'safety' cabinets found in the UK in the last six years is recorded. Only two of the nine units tested approached the containment of aerosols achieved by a good class I (exhaust protective) cabinet. The others were potentially hazardous if used with pathogenic material. The National Sanitation Foundation and the British Standards Institute have now laid down adequate specifications based on biological containment, and hopefully the conforming cabinets will be much better; even so, the purchase of a cabinet must be undertaken with care, and the cabinet requires frequent monitoring during use and after servicing.

Laminar airflow is airflow in which the entire body of air within a confined area moves with uniform velocity along parallel lines with a minimum of eddies. Whitfield (1962) applied the principle to clean room design, and McDade et al. (1969) reviewed the topic and stated the following design goals:

(a) airflow of uniform velocity and direction across any given cross section; and

(b) all air entering the system must be filtered through

a high efficiency (HEPA) filter.

Small, so-called laminar flow enclosures are now available for the pharmacy and laboratory. These differ from the clean room in a major respect-an interface with room air-and so are subject to external air movement. There are two types of enclosure, the clean bench and the safety cabinet, which differ in the vital property of operator protection.

\section{Clean bench}

This protects the work. A stream of sterile air blows across the work past the operator and into the room. Such a unit is the opposite of a safety cabinet, and some large USA laboratories have banned their use to avoid confusion. The clean bench can be of use in pharmacy, however, and has the added value of cleaning the room air, which passes through the HEPA filter up to three times per minute.

\section{Class II 'safety cabinet'}

This is used to protect both the operator and the

Received for publication 16 October 1978 work from airborne contamination. The biohazard application of laminar flow is very demanding because of the interface between air in the cabinet with that in the laboratory and the pressure balance in the air exhaust system. The airflow is not strictly laminar. The workspace is flushed with a unidirectional downward flow of sterile air, usually at a negative pressure to the laboratory so that unsterile air is drawn in to try to stabilise the interface and prevent leaks outward. The exhaust air passes through a plenum (under either negative or positive pressure) to the fan, then $10-20 \%$ may be dumped through a HEPA exhaust filter, while the remainder is recirculated through the HEPA supply filter into the workspace. Total exhaust may be specified for work with chemicals. Freestanding cabinets are depicted in Figures 1 and 2. Figure 1 depicts a recirculating unit. The air is exhausted from the workspace via slots sited in front and behind a solid worksurface. The air returns to the filters through a positive-pressure plenum sited behind the workspace. The fan is sited in the dirty airstream, and the ratio of the exhaust to supply filter sizes determines the amount of exhaust air, and so the amount of room air sucked into the system. Figure 2 shows a unit with two fans and filters set for a total dump of the exhaust air. Air enters at the top, passes through the workspace where it is joined by some room air, and is exhausted via a short negative-pressure plenum through a HEPA filter by the second fan, which is thus in the clean airstream.

Both the units are freestanding and have a solid worksurface. Alternative designs include benchmounting, perforated worksurfaces, fans mounted above the supply filter, recirculating units with two fans and filters, and slanted front windows. 


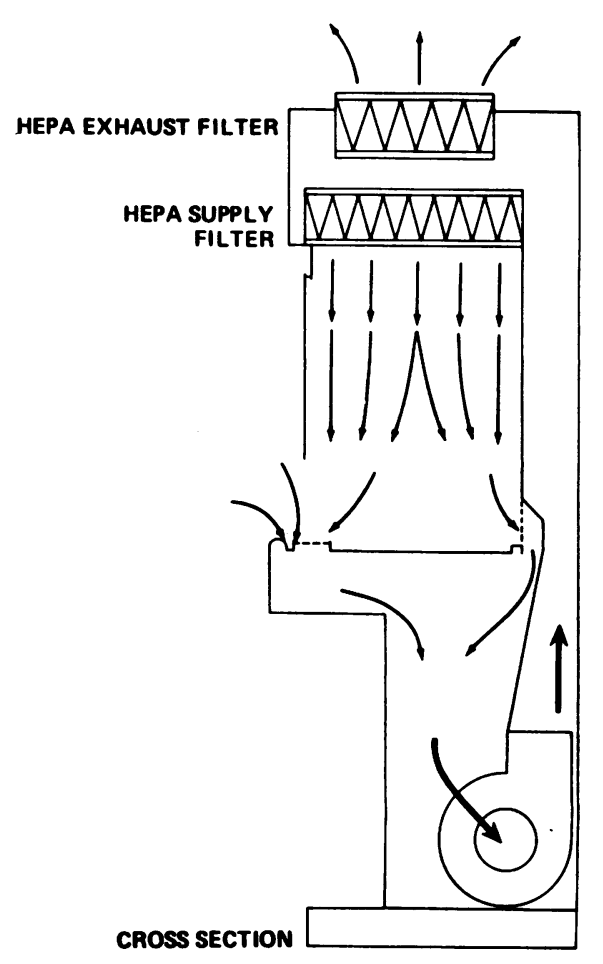

Fig. 1 A recirculating laminar flow cabinet with partial air-dump. Note contaminated fan.

McDade et al. (1968) tested a unit with a slanted window, in which the inflow of room air was overcome by turbulence from the downflow air as it expanded into the space at the bottom of the window and leaked out along its edge. They noted that if the exit for exhaust air was at the back the whole stream of downflow air was moved backwards. Staat and Beakley (1968) found turbulence around the lower edge of the window in another unit. Coriell and McGarrity (1968) described a unit with a downflow of $0.5 \mathrm{~m} / \mathrm{s}$, an inflow of $1 \mathrm{~m} / \mathrm{s}$, and $90 \%$ recirculation of the air, which contained aerosols well. However, the unit had a plenum that carried contaminated air under pressure, and McGarrity and Coriell (1974) described an improved version with the dirty air under negative pressure.

Clark and Mullen (1978) visualised the airflows within units with glass walls by Schlieren photography. They noted that air leaked out after movements in and out of the cabinet, and that the use of a gas burner 'pushed' air out. Air was also expelled as the unit was switched on, and the hot air inside the unit expanded into the cooler laboratory when the unit was switched off.

Barkley (1972) described a comprehensive design

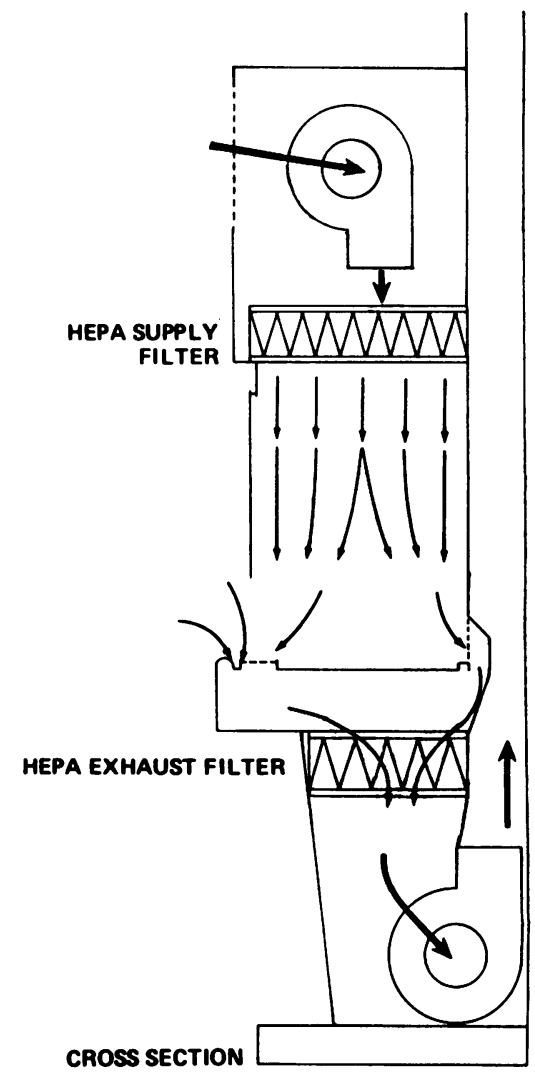

Fig. 2 A total dump laminar flow cabinet. Note independent fans.

study of laminar flow 'biohazard' cabinets done in a specially ventilated laboratory. He used microbial challenges and tested different airflows. His methods and many of his design concepts have been incorporated into the National Sanitation Foundation (1976). Standard for Class II Biohazard cabinets.

A test programme for safety cabinets was started at Papworth in 1971 for the Department of Health and Social Security. The test methods (Newsom, 1974) were based on the containment of an aerosol of Bacillus subtilis spores, generated in a micronebuliser operated at 10 psi pressure. By a serendipity, Barkley (1972) used a similar micronebuliser operated at the same pressure and $B$. subtilis spores. Although open-fronted exhaust (class I) cabinets were the prime aim of the survey, some class II units were tested, and others have been inspected on site in laboratories. The paper describes the results of these tests and observations. 


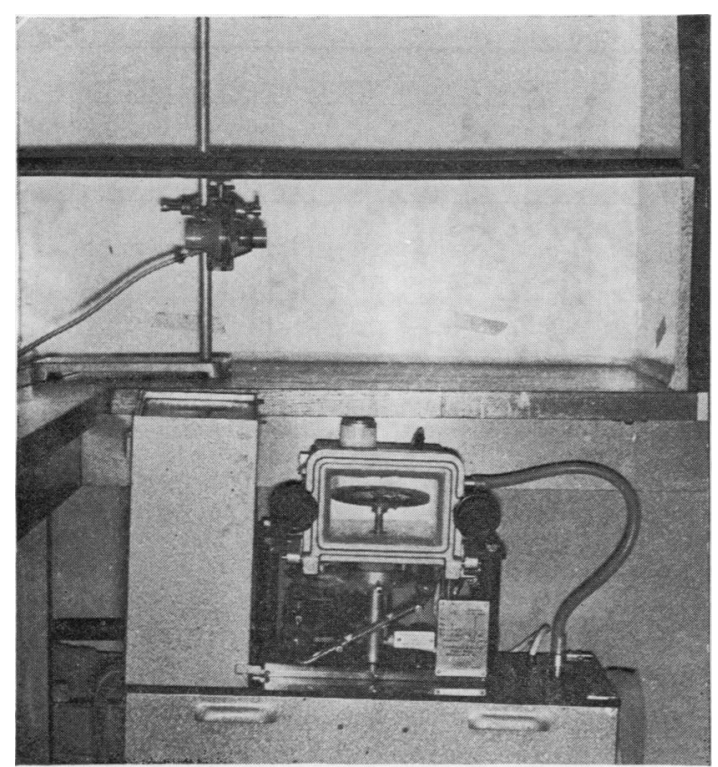

Fig. 3 Bacteriological containment test equipmentmicronebuliser above and slit sampler beneath.

\section{Material and methods}

\section{MICROBIAL TESTS}

Spores were used as tracers to test protection of the operator from aerosols liberated in the cabinet, and protection of the work from aerosols both within the cabinet and in the laboratory.

Operator protection was measured by liberating an aerosol of $2 \times 10^{4}$ spores from the micronebuliser sited $15 \mathrm{~cm}$ from the front opening and $15 \mathrm{~cm}$ above the floor on the left side of the cabinet with its axis pointing across the cabinet (Fig. 3). The aerosol was generated in a 10-second burst, and 551 of laboratory air was sampled in a slit sampler placed in front of the cabinet level with its floor, started as soon as the aerosol began, and run for 2 minutes. Tests were run in sets of twelve. Additional sets were done with the micronebuliser pointing forwards, in various other sites, with $2 \times 10^{6}$ spores, and with the operator simulating work by opening and closing a dozen screw-capped bottles during the test.

Product protection was tested by:

(a) liberating an aerosol from the standard site within the cabinet and exposing two $25 \mathrm{~cm}^{2}$ assay dishes full of nutrient agar under the track of the spray for 2 minutes. The left-hand dish was sited approximately $15 \mathrm{~cm}$ from the nozzle of the micronebuliser, and the right-hand one was approximately $75 \mathrm{~cm}$ away (depending on cabinet width);

(b) liberating an aerosol from the laboratory $15 \mathrm{~cm}$ from the working aperture, and sampling with a sampler within the cabinet;

(c) exposing agar plates along the front edge of the worksurface for 1-hour periods during the working day.

\section{AIRFLOW TESTS}

Some airflow measurements across the front aperture, and sections of the downflow air, were done using an electronic or a thermoanemometer. In addition, a few 'profiles' were run on the downflow of several cabinets using a prototype computerised thermister anemometer invented by Braeme and Bruce (1978, personal communication), able to plot a horizontal transection of airflows based on the averages of several thousand point readings.

\section{CABINETS TESTED}

A wide, but not comprehensive, range of cabinets was tested or observed (at least three more are awaited). Tests were done on four prototypes (three were not marketable, and the fourth was made privately for the Agricultural Research Council) and five commercially available models, including two made in the UK (by the same firm), two designed in the USA but made in Europe, and one obtainable direct from the USA. Three other models were partially tested-on site in laboratories that precluded bacterial tests.

\section{Results}

\section{MICROBIAL TESTS}

The results are presented in three tables, viz, Table 1-four prototypes (Nos. 1, 2, 3, 3a); Table 2-two models (and a Papworth modification) from a UK manufacturer (Nos. 4, 4a, 5); Table 3-three American-designed units (Nos. 6, 7, 8). The results of liberating aerosols within the cabinets and sampling outside are presented under 'operator protection'. Tests were done in sets of 12 , and an average count of viable particles per 551 of air is recorded, together with the maximum of each set to indicate whether the average concealed a single hazardous leak. As the tests were not done in a specially ventilated room some background counts were obtained, but never above 5 particles per 551 , and usually 1 or 0 , and these are recorded in the tables. Micronebuliser controls (not recorded) were run at the end of each day to check that adequate challenges had been delivered. 'Product protection' states the results of: (a) sets of 12 tests with the micronebuliser in the laboratory and the sampler in the cabinet; (b) sets of three tests with the two $25 \mathrm{~cm}^{2}$ assay dishes recorded as an average count per dish; and (c) average counts per plate from plates exposed hourly during a working day. 
Table 1 Prototype cabinets

\begin{tabular}{|c|c|c|c|c|c|c|c|c|}
\hline \multirow[b]{3}{*}{ Challenge } & \multicolumn{8}{|c|}{ Air counts-viable particles per 55 litres } \\
\hline & \multicolumn{2}{|c|}{ Cabinet 1} & \multicolumn{2}{|c|}{ Cabinet 2} & \multicolumn{2}{|c|}{ Cabinet 3} & \multicolumn{2}{|c|}{ Cabinet $3 a$} \\
\hline & $A v$ & $\operatorname{Max}$ & $A v$ & $\operatorname{Max}$ & $A v$ & $\operatorname{Max}$ & $A v$ & $\operatorname{Max}$ \\
\hline \multicolumn{9}{|l|}{ Operator protection tests } \\
\hline Spray crossways $-15 \mathrm{~cm}$ in & 2 & 4 & $0 \cdot 2$ & 1 & 9 & - & 22 & 29 \\
\hline As above + working & 5 & 11 & $0 \cdot 1$ & 1 & - & - & 15 & 31 \\
\hline As above $+10^{6}$ spores & $200+$ & $200+$ & 0.5 & 2 & - & - & 12 & 16 \\
\hline Spray forwards $15 \mathrm{~cm}$ in & 8 & 41 & $0 \cdot 1$ & 1 & 一 & - & 10 & 13 \\
\hline Spray forwards $2.5 \mathrm{~cm}$ in & 14 & 58 & $50+$ & $200+$ & 一 & - & $500+$ & - \\
\hline As above + walking & 80 & $100+$ & $\mathbf{X}$ & $\mathbf{X}$ & - & 一 & - & - \\
\hline Sonicator in cabinet & 18 & 41 & 0 & 0 & - & - & - & - \\
\hline Exhaust effluent (filtered) & 0 & 0 & 0 & $\mathbf{0}$ & - & 一 & - & - \\
\hline Room air before tests & $0 \cdot 3$ & 4 & $0 \cdot 2$ & 1 & $\mathbf{0}$ & $\mathbf{0}$ & & 0 \\
\hline \multirow{4}{*}{$\begin{array}{l}\text { Product protection tests } \\
\text { Sampler in cabinet } \\
\text { Av count on } 25 \mathrm{~cm} \text { plate } \\
\text { Av counts on hourly plates }\end{array}$} & & & & & & & & \\
\hline & 1 & 4 & 一 & - & 一 & - & 一 & 一 \\
\hline & $200+$ & & 2 & & - & - & 17 & 一 \\
\hline & - & 一 & $2 \cdot 5$ & & - & - & - & - \\
\hline
\end{tabular}

Av $=$ average $;$ Max $=$ maximum counts recorded $X=$ unnecessarily hazardous to test.

Table 2 UK-made cabinets

\begin{tabular}{|c|c|c|c|c|c|c|}
\hline \multirow[b]{3}{*}{ Challenge } & \multicolumn{6}{|c|}{ Air counts-viable particles per 55 litres } \\
\hline & \multicolumn{2}{|c|}{ Cabinet 4} & \multicolumn{2}{|c|}{ Cabinet $4 a$} & \multicolumn{2}{|c|}{ Cabinet 5} \\
\hline & $A v$ & $\operatorname{Max}$ & $A v$ & $\operatorname{Max}$ & $A v$ & $\operatorname{Max}$ \\
\hline \multicolumn{7}{|l|}{ Operator protection tests } \\
\hline Spray crossways $-15 \mathrm{~cm}$ in & $0 \cdot 3$ & 2 & 1 & 4 & 0.3 & 1 \\
\hline As above + working & 2 & 5 & 0.4 & 1 & 0.5 & 2 \\
\hline As above $+16^{6}$ spores & 10 & 19 & 4 & 6 & 1 & 4 \\
\hline Spray forwards $15 \mathrm{~cm}$ in & $1 \cdot 4$ & 2 & 0.8 & 2 & $400+$ & $400+$ \\
\hline Spray forwards $2.5 \mathrm{~cm}$ in & 26 & 84 & $\mathbf{x}$ & & $\mathbf{X}$ & \\
\hline As above + walking & 109 & 212 & $\mathbf{X}$ & & $\mathbf{X}$ & \\
\hline Sonicator in cabinet & 6 & 24 & $\mathbf{X}$ & & 0.5 & 2 \\
\hline Exhaust effluent & 5 & 5 & - & 一 & 0.2 & 1 \\
\hline Room air before tests & 0 & 0 & - & 一 & 1 & 1 \\
\hline \multirow{4}{*}{$\begin{array}{l}\text { Product protection tests } \\
\text { Sampler in cabinet } \\
\text { Av counts on } 25 \mathrm{~cm} \text { plate } \\
\text { Av counts on hourly plates }\end{array}$} & & & & & & \\
\hline & $\mathbf{0}$ & $\mathbf{C}$ & 一 & 一 & $\overrightarrow{0}$ & 一 \\
\hline & $-^{1}$ & & $\longrightarrow$ & & $800+$ & \\
\hline & 一 & & & & O & \\
\hline
\end{tabular}

$\mathbf{A v}=$ average $; \mathbf{M a x}=$ maximum $\mathbf{X}=$ unnecessarily hazardous to test.

The tests spanned six years, and the system was gradually improved, so not all tests were run on each cabinet. Tests on Nos. 3 and $3 a$ were strictly limited by time as they were done 'on location'; tests marked $\mathrm{X}$ were omitted as the results already available indicated needless contamination of laboratory air.

\section{INDIVIDUAL CABINETS}

No. 1 is seen in Figure 4. It was a benchmounted, recirculating cabinet with two fans sited side by side in the dirty airstream above the supply filter. Air was exhausted from the workspace through a fully perforated floor into a very flat space connected at the back with the return air plenum sited behind the workspace. Approximately $10 \%$ of the air was dumped through an exhaust HEPA filter. Serious leaks of aerosols occurred in all but the first test, and different but also bad results were obtained with the micronebuliser in a mirror image site on the right side of the cabinet, indicating some lack of fan balance. Product protection was poor. Particle counts done with a Coulter counter showed that the air entering the workspace from the supply filter was full of particles, and indeed the filter was only $90 \%$ efficient instead of $99.997 \%$. This was later found to be due to a defective filter mounting rather than to the filter itself. The downflow of air was reasonably 
Table 3 United States-designed cabinets

\begin{tabular}{|c|c|c|c|c|c|c|}
\hline \multirow[b]{3}{*}{ Challenge } & \multicolumn{6}{|c|}{ Air counts-viable particles per 55 litres } \\
\hline & \multicolumn{2}{|c|}{ Cabinet 6} & \multicolumn{2}{|c|}{ Cabinet 7} & \multicolumn{2}{|c|}{ Cabinet 8} \\
\hline & $A v$ & $\operatorname{Max}$ & $A v$ & $\operatorname{Max}$ & $A v$ & $\operatorname{Max}$ \\
\hline \multicolumn{7}{|l|}{ Operator protection tests } \\
\hline Spray crossways $-15 \mathrm{~cm}$ in & 1 & 4 & $0 \cdot 3$ & 1 & $0 \cdot 3$ & 1 \\
\hline As above + working & 0.8 & 3 & 1 & 2 & 1 & 9 \\
\hline As above $+10^{6}$ spores & 14 & 30 & 0 & $\overrightarrow{0}$ & 3 & 5 \\
\hline Spay forwards $15 \mathrm{~cm}$ in & 0.7 & 1 & 0.6 & 3 & $300+$ & $300+$ \\
\hline Spray forwards $2.5 \mathrm{~cm}$ in & - & 一 & 1 & 6 & $\mathbf{X}$ & $\mathbf{X}$ \\
\hline As above + walking & 6 & 20 & 2 & 5 & $\mathbf{x}$ & $\mathbf{X}$ \\
\hline Sonicator in cabinet & 4 & 11 & 1 & 4 & $\mathbf{X}$ & $\mathbf{X}$ \\
\hline Exhaust effluent (filtered) & 0.5 & 2 & $\mathbf{0}$ & 0 & 0.3 & 1 \\
\hline Room air before tests & 2 & 5 & 1 & 2 & 1 & 2 \\
\hline \multirow{4}{*}{$\begin{array}{l}\text { Product protection tests } \\
\text { Sampler inside cabinet } \\
\text { Av count on } 25 \mathrm{~cm} \text { plate } \\
\text { Av count on hourly plates }\end{array}$} & & & & & & \\
\hline & $\longrightarrow$ & - & $\mathbf{0}$ & $\mathbf{0}$ & 1.9 & 13 \\
\hline & $0 \cdot 5$ & & 15 & & $600+$ & \\
\hline & & & - & & 2 & \\
\hline
\end{tabular}

Av $=$ average $;$ Max $=$ maximum $\mathbf{X}=$ unnecessarily hazardous to test.

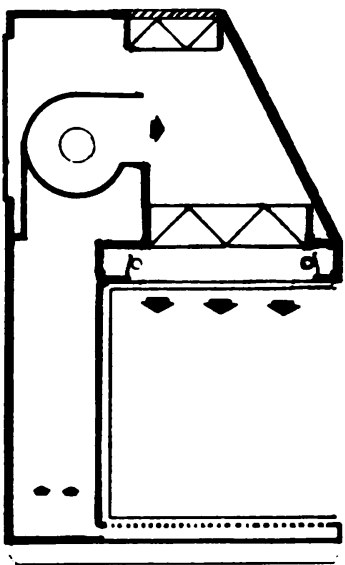

Fig. 4 Cabinet No. 1. Benchmounted, recirculating.

balanced just beneath the supply filter but at floor level was very unbalanced and so allowed an excessive ingress of room air across the worksurface. No. 2 was a benchmounted, recirculating cabinet, which differed from no. 1 in having a solid worksurface with extract slots before and behind, and a good supply filter mounting. Both operator and product protection were excellent, although placing the micronebuliser $2.5 \mathrm{~cm}$ behind the working aperture allowed a major leak.

Nos 3 and $3 a$ were freestanding units with a perforated worksurface. Both had two fans with separate control gear, which depended on the operator for careful balancing. Cabinet 3 is seen in Figure 5. There was no exhaust vent, that is, total recirculation of the air, but the bottom fan could be

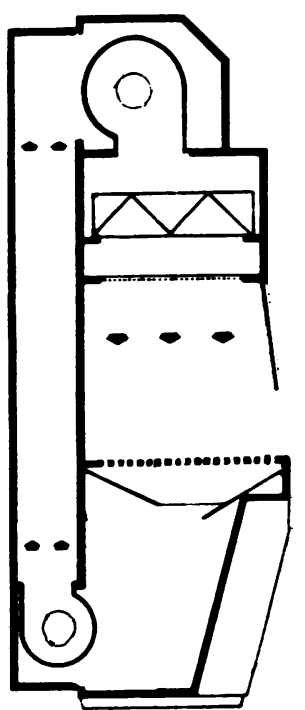

Fig. 5 Cabinet No. 3. Freestanding, total recirculation.

set to suck air into the machine. Quite where this air went was not clear; it was said to build up as pressure behind the supply filter! However, when the supply fan was set to produce $0.5 \mathrm{~m} / \mathrm{s}$ downflow and the exhaust fan to produce $0.5 \mathrm{~m} / \mathrm{s}$ inflow, spores leaked out. The manufacturer later confirmed that this was due to a faulty return air plenum, which must have been under pressure. The unit was then modified by the addition of a second HEPA filter to a total exhaust state similar to that in Fig. 2 (No. 3a). Tests with the fans set to give $0.5 \mathrm{~m} / \mathrm{s}$ downflow and $0.75 \mathrm{~m} / \mathrm{s}$ inflow again revealed significant leaks. This was attributed to restrictions placed on the outflow 
of air from the workspace by the perforations in the worksurface.

No. 4 was a benchmounted, recirculating model with a fully perforated worksurface similar to that of No. 1 (Fig. 4) except that it had a deeper space beneath the worksurface, a single fan, and no front window. Protection of the operator was marginal with the micronebuliser $15 \mathrm{~cm}$ in, and gross leaks occurred with the spray $2.5 \mathrm{~cm}$ in, which were accentuated when the technician walked past. Product protection was remarkably good. The unit was improved slightly by covering $75 \%$ of the front with polythene, together with a $15 \mathrm{~cm}$ strip across the centre of the floor (No. 4a).

No. 5 was No. 4 redesigned to include a front window and a solid section in the floor. Unfortunately, the latter was too wide and placed so near the front that it allowed only a small front extract slot and a large rear one. The downflow air was deflected backwards, and both operator and product protection were worse than before.

No. 6 was a freestanding, recirculating unit with a solid worksurface with exhaust slots front and back, as in Fig. 1, but provided in addition with an internal 'air curtain' to prevent ingress of room air into the workspace. Operator protection was marginal with leaks from the $10^{6}$ challenge and major leaks with the micronebuliser $2.5 \mathrm{~cm}$ in. Product protection was excellent.

No. 7 was a freestanding, recirculating model fitted with both supply and exhaust fans and filters (Fig. 6). It had a negative-pressure plenum for contaminated air. The fans were preset (controls could not be altered) and interlinked by pressure-sensitive switches connected to an audible alarm. The worksurface was in three sections: in front a series of large slots projecting into the room, then a $15 \mathrm{~cm}$ wide solid area, and behind that a perforated surface. This unit gave excellent operator and product protection.

No. 8 was a benchmounted, recirculating unit fitted with a single fan above the supply filter (as in Fig. 4). The worksurface was solid with extract slots in front and behind, and an internal 'air curtain' was achieved by shaping the front window. Although it was said to have passed the American National Sanitation Foundation tests (qv) both operator and product protection were poor. The simulated work test produced a much greater leak than the static test. The results were explained later when it was found that the fan used was specified for the 60 cycle current of the USA rather than for 50 cycle AC.

\section{AIRFLOWS}

The following units were seen in sites that precluded spore-spraying, and so airflow tests alone were done. No. 9 was a freestanding unit with a total dump of

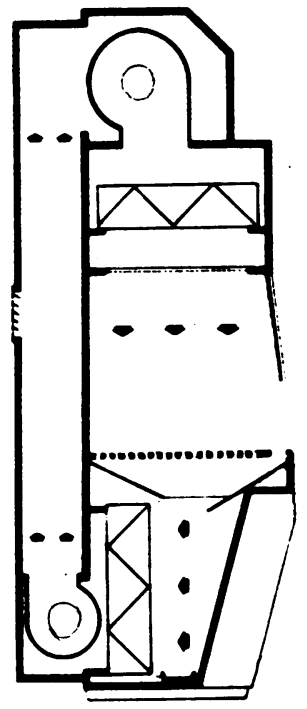

Fig. 6 Cabinet No. 7. Freestanding, recirculating.

exhaust air fitted with two fans and filters with independent controls (Fig. 7). When tested 'in use', it was found to be blowing radioactive air into the pharmacy. Even if set up correctly, one could switch on the supply fan before the exhaust, and the rheostat control for the latter was exposed near the floor where it might easily be inadvertently moved. The exhaust fan was sited in the dirty airstream, and there was a positive-pressure plenum of dirty air between it and the exhaust filter. The latter was sited

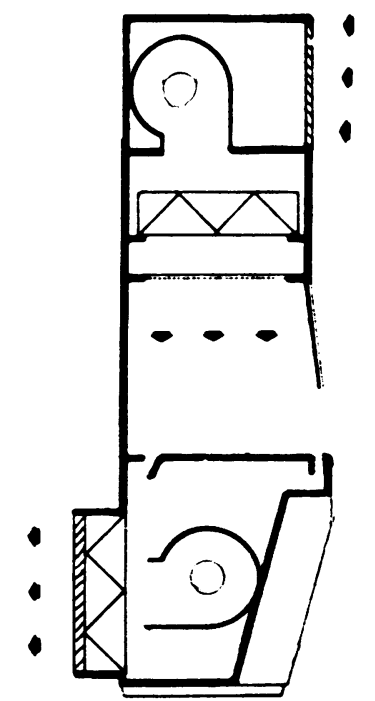

Fig. 7 Cabinet No. 9. Freestanding, total exhaust. 
behind the unit, which was so heavy that it was almost impossible to move it for filter changing or inspection.

Nos 10 and 11 were two freestanding, recirculating models from a prominent USA manufacturer. The automated thermoanemometer was used by $\mathrm{Mr}$ Breame to record the vertical airflow, from the back to the front of the cabinet at the upper edge of the working aperture. Three transects were done on each, one each side and one in the centre. Both models showed considerable fall-off of airflow halfway towards the back of the cabinets, presumably due to an air rebound off the solid part of the worksurface. The earlier model also showed a marked velocity reduction and variation from point to point, signifying turbulence in the central transect. Closer inspection revealed that the cabinet roof contained two filters separated by a metal band.

\section{Discussion}

The use of $B$. subtilis spores and a micronebuliser (Newsom, 1974) was very fortunate because Barkley (1972) used a similar challenge which has been incorporated into the American National Sanitation Foundation (NSF) standard and will also be used in the British Standard as a 'type test'. Barkley used a Vaponefrin (Fisons) nebuliser operated at the same pressure as the Bird used here, and it delivers similar volumes of suspension although in 8.5 rather than 51 air/minute.

The NSF 'operator protection' challenge is $10^{8}$ spores, liberated $35 \mathrm{~cm}$ above the worksurface with the micronebuliser pointing towards the front of the cabinet $10 \mathrm{~cm}$ behind the window. Thus any turbulence around the lower edge of the window will cause a leakage of spores. On the other hand, my spray site $10 \mathrm{~cm}$ above the floor and $15 \mathrm{~cm}$ from the front represents a more likely actual working site within the cabinet. The NSF challenge of $5-40 \times$ $10^{8}$ spores is considerably more than my $12-24 \times$ $10^{6}$, and their test samples twice the volume of laboratory air. An acceptable NSF pass would be equivalent to 2 particles per test in my system, a figure occasionally found in control air. Bad cabinets, however, usually produced very much higher counts than this, and anyway strict comparisons are impossible because of the different sites of liberation of the aerosols. I have taken an average count of 5 particles to indicate poor operator protection, and an occasional leak of above 5 but an average of below 5 to indicate marginal protection.

The NSF cross-contamination protection is similar to my placing two large settle plates on the floor beneath an aerosol. The only tests done here that might seem unrealistic were those with the nebuliser
$2.5 \mathrm{~cm}$ behind the working aperture. Nonetheless cabinet 7 contained this aerosol, as do all currently available class I units with airflows across the working aperture above $0.75 \mathrm{~m} / \mathrm{s}$. The results with cabinet 2 , which passed all but the $2.5 \mathrm{~cm}$ in test, at least emphasise the need to work well within the cabinet.

These tests and observations revealed a sad record of the state of 'class II biohazard units' currently seen in the UK. However, the cabinets tested were a random selection and do not represent all those available; for example, no Baker cabinets were spore tested; and, furthermore, cabinets built to the NSF or BSI standards should soon become available. Meanwhile the only commercial cabinet to be tested that passed (No. 7) was made by Gelman (Milan) Ltd. No. 2, the next best, was an ARC prototype (Egan, 1978, personal communication). R. P. Clarke (1978, personal communication), who has also tested some of these units by a different system, has come to similar conclusions.

Some obvious design faults were noted in the survey. Faulty filter mounts (cabinet 1) and contaminated air leaking from a pressurised plenum (cabinets 3 and 3a) suggest the need for a filter below the worksurface, mounted in such a way as to eliminate any bypass of air, with the fan beyond it so that all contaminated air is under negative pressure and the fan itself is in the clean airstream. Such a design is already incorporated in the National Cancer Institute NCB cabinet. The interface of downflow air with the inflow air from the laboratory across the working aperture is a crucial point; turbulence between the two airstreams (as in cabinets 3 and $3 a$ ) creates leakages into the laboratory. The two airstreams were carefully separated in cabinet 7 , and this may explain its excellent containment property. Balanced airstreams must depend on the design of the working aperture and the relative velocities of the airflows, which in turn will depend on the fan system. A single fan recirculating much of the air would be best as it will be self-balancing, and recirculated clean air makes for prolonged filter life. The worst possible state (seen in cabinets 3 and 9) is to have two fans (and two filters) with independent controls movable at the operator's whim. Even if correctly set initially, the balance may be upset as the two filters will load at different rates. Staat and Beakley (1968) found that a slanted window also created increased turbulence as the air expanded to fill the space available, while McDade et al. (1968) noted the value of an aerodynamic sill in preventing turbulence. Barkley (1972) found less turbulence with lower airflows $(0.4 \mathrm{~m} / \mathrm{s}$ downflow and $0.35 \mathrm{~m} / \mathrm{s}$ inflow). However, Chatigny and Clinger (1969) showed that a person walking at $2 \mathrm{mph}$ created backdraughts of 
$0.85 \mathrm{~m} / \mathrm{s}$, and Rake (1978) showed that as controlled crossdraughts increased above $0.5 \mathrm{~m} / \mathrm{s}$ leakage of spores increased on a logarithmic scale. She noted that air-conditioning vents and even open windows and doors readily produced such draughts and advocated the siting of cabinets in quiet areas.

The interface of airflow with worksurface and extract is also a crucial design area. The computeranemometer tests showed that the back-pressure from a solid fioor disturbs the airstream at least to the upper edge o $/$ the working aperture. A fully perforated worksurface might be an improvement, but two of the units were fitted with such a floor above a shallow space with a rear extract slot, and in both the airflow was moved towards the back. The Gelman unit had a reasonable number of large perforations across the worksurface, but the similar perforations in cabinet 3 were said to be inadequate and to cause a back-pressure on the airflow. Most of the units tested had an evenly balanced flow of sterile air immediately beneath the supply filter. However, the dangers of obstructions to the airflow were seen in cabinet 11. Bruce (personal communication, 1978) has also recorded turbulence in airflows where other obstructions, for example, fluorescent lamps, are mounted within the cabinet. To avoid turbulence, the supply filter (or diffuser) should extend across the whole work area, and the airflow must not be obstructed.

The laminar flow safety cabinet is thus a complex design problem, which is further complicated by international considerations: one model was made in Europe to an American design, but with slight and crucial differences, while another had an inappropriate fan. Even a good cabinet may be damaged in transit; filters and filter mountings are particularly at risk.

The testing of cabinets, both on installation and in use (especially after filter changing), is thus of vital importance. Barkley (1973) tested 96 units of eight different makes, on-site in American laboratories, and found that 49 had serious filter leaks and 61 had unacceptable airflows. Purchase of a cabinet, therefore, implies that the user must buy test equipment. Spore tests are not applicable to the in-use situation. Foord and Lidwell (1975) used sodium iodide particles instead.

Tests of filter/mounting competence are usually best done with di-octylphthalate smoke and a photometer, although a simple indication of gross leakage can be provided by comparing the $0.5 \mu \mathrm{m}$ particle counts in the cabinet and the laboratory using a light-scattering photometer. A thermoanemometer is needed to measure airflows; but a true measurement of the airflow across the working aperture is impossible as it varies continuously from virtually nil at the top to maximal at the bottom. An estimate can be obtained by subtracting measurements of downflow air from those of the air in the exhaust plenum. The whole subject of testing is clearly described in Certification of Class II (Laminar Flow) Biological Safety Cabinets-the National Cancer Institute (obtainable from the National Audiovisual Centre (GSA), Washington DC 20409, USA).

There is no doubt that good class II cabinets have been developed in the USA as a result of the major research programme on cancer. The need, however, for cabinets in the hospital routine laboratory is for operator protection, and the class I or exhaust protective cabinet is a much simpler machine, more easily designed, tested, and maintained. Furthermore, tests done on several well-engineered class I cabinets operating with an airflow of above $0.75 \mathrm{~m} / \mathrm{s}$ across the working aperture gave some degree of product protection, probably because the speed of the airstream means that particles become entrained and impacted on the exhaust filter. For these reasons the Code of Practice of the Howie working party (1978) came down strongly in favour of a class I cabinet to provide operator protection in the routine bacteriology laboratory. A need may remain, however, for class II cabinets in other areas, the radio-pharmacy for instance, or the tissue culture laboratory, and it is to be hoped that more correctly designed equipment will soon become available. However, in both class I and class II cabinets the protection ceases if the fan fails, and the operator is not protected from direct contact with the work merely from aerosols. Thus the class III (totally enclosed) unit remains mandatory for work with the highly dangerous 'category A' pathogens.

I am very grateful to the manufacturers of the cabinets for the loan of their equipment, and to Inter Health Authority Study group 9 of the Department of Health and Social Security Engineering Division for supporting this work.

\section{References}

Barkley, W. E. (1972). Evaluation of controlled airflow systems for environmental safety in biomedical research. Ph.D. thesis, University of Minnesota.

Barkley, W. E. (1973). Biohazards in Biological Research, edited by A. Hellman, M. N. Oxman, and R. Pollack, p. 339. Cold Spring Harbor Laboratory, Cold Spring Harbor, N.Y.

Chatigny, M. A., and Clinger, D. I. (1969). Contamination control in aerobiology. In An Introduction to Experimental Aerobiology, edited by R. L. Dimmick, and A. B. Ackers, p. 194. Wiley-Interscience, New York. 
Clark, R. P., and Mullen, B. J. (1978). Airflows in and around linear downflow 'safety' cabinets. Journal of Applied Bacteriology, 45, 131-136.

Coriell, L. K., and McGarrity, G. J. (1968). Biohazard hood to prevent infection during microbiological procedures. Applied Microbiology, 16, 1895-1900.

Foord, N., and Lidwell, O. M. (1975). Airborne infection in a fully air-conditioned hospital. Journal of Hygiene, 75, $15-56$.

Howie, Sir James (1978). A Code of Practice for the Prevention of Infection in Clinical Laboratories (Report of the Working Party). HMSO, London.

McDade, J. J., Phillips, G. B., Sivinski, H. D., and Whitfield, W. J. (1969). Principles and applications of laminar-flow devices. In Methods in Microbiology, edited by J. R. Norris and D. W. Ribbons, Vol. 1, pp. 137-168. Academic Press, London.

McDade, J. J., Sabel, F. L., Akers, R. L., and Walker, R. J. (1968). Microbiological studies on the performance of a laminar-flow biological safety cabinet. Applied Microbiology, 16, 1068-1092.

McGarrity, G. I., and Coriell, L. L. (1974). Modified laminar flow biological safety cabinet. Applied Microbiology, 28, 647-650.

National Sanitation Foundation (1976). Standard No. 49, Class II (Laminar Flow) Biohazard Cabinetry. Ann Arbor, Michigan.

Newsom, S. W. B. (1974). A test-system for the biological safety cabinet. Journal of Clinical Pathology, 27, 585-589.

Rake, B. W. (1978). Influence of crossdrafts on the performance of a biological safety cabinet. Applied and Environmental Microbiology, 36, 278-283.

Staat, R. H., and Beakley, J. W. (1968). Evaluation of laminar flow cabinets. Applied Microbiology, 16, 1478-1482.

Whitfield, W. J. (1962). Laminar flow. Technical Report SC4673(RR). Sandia Corporation, Albuquerque, New Mexico.

Requests for reprints to: Dr S. W. B. Newsom, Department of Bacteriology, The John Bonnett Clinical Laboratories, Addenbrooke's Hospital, Cambridge CB2 2QQ, UK. 